\title{
Baltic Sea ocean climate: an analysis of 100 yr of hydrographic data with focus on the freshwater budget
}

\author{
Peter Winsor ${ }^{1, *}$, Johan Rodhe ${ }^{1}$, Anders Omstedt ${ }^{2}$ \\ ${ }^{1}$ Department of Earth Sciences/Oceanography, Göteborg University, Göteborg, Sweden \\ ${ }^{2}$ Department of Earth Sciences/Oceanography, Göteborg University, Göteborg, Sweden and SMHI, Norrköping, Sweden
}

\begin{abstract}
The Baltic Sea climate is analysed based upon long-term oceanographic measurements. The objective of the work is to study the natural variability of present day climate with focus on the freshwater budget. The results are designed to be used for validation of climate models and for discrimination of the significance of modelled climate change scenarios. Almost $100 \mathrm{yr}$ of observations are used in the study, including data for river runoff, water exchange through the Danish Straits (as calculated from river runoff and from sea level data from the Kattegat), salinity data from the Baltic Sea and the Kattegat, and oxygen content in the deep Baltic Sea. The analyses illustrate that freshwater supply to the Baltic shows large variations on time scales up to several decades. The long-term variations in freshwater storage are closely correlated to accumulated changes in river runoff. This indicates strong positive feedback between the amount of outflowing surface water from the Baltic Sea and the salinity of the inflowing Kattegat water. One implication of the study is that climate control simulations must cover several decades, probably up to $100 \mathrm{yr}$ in order to capture the natural variability of present day climate. Also, models designed to study climate change for the Baltic Sea probably need to start integrating from the present day.
\end{abstract}

KEY WORDS: Baltic Sea $\cdot$ Climate $\cdot$ Salinity $\cdot$ Freshwater $\cdot$ River runoff $\cdot$ Oxygen

\section{INTRODUCTION}

Efforts to model possible future climate change have increased during recent years. The SWECLIM programme (Swedish regional climate modelling programme) aims at downscaling global climate change simulations achieved using low-resolution general circulation models. The regional model improves local scenarios by taking into account topographic features as well as a realistic distribution of lakes and seas etc. Climate change modelling involves control runs, simulating present day climate, and scenario runs taking into account estimated changes in the composition of the atmosphere. Historical climate data play an impor-

*E-mail: pewi@oce.gu.se tant part in the process, firstly validating the control run, and secondly for testing the significance of climate change scenarios in relation to the variability in present day climate. The demands on models used for climate change scenarios differ in several ways from those on models used for operational purposes. A model for operational purposes simulates detailed development from a given initial state during a limited time, whereas a climate model must be able to give a statistically correct solution, independent of initial conditions, and must also have long-term stability. Furthermore, an operational model can be tuned for present day conditions, whereas a climate model must rely more on correct treatment of processes involved than on tuning.

The objective of this study is to analyse the natural variability of present day large-scale Baltic Sea climate 
and its relation to the forcing of the system. The focus is on the freshwater budget. We use long time series $(\sim 100 \mathrm{yr})$ of river runoff to the Baltic Sea, water exchange between the Baltic Sea and the North Sea (calculated from sea level and river runoff data), and of salinity and oxygen content in the Baltic Sea. The results are intended to be used in the process of validating climate model control runs and also to test the significance of climate change scenarios. For this reason, only observed external variables are used and not, for example, the salinity of the Baltic Sea entrance area, which is in part determined by the state of the Baltic.

The outline of this paper is as follows. After a brief presentation of the large-scale oceanography of the Baltic Sea and its governing processes (Section 2), we present the different data series used in the analysis and define some ocean climate variables (Section 3). Section 4 presents time series and some statistical properties of forcing and ocean climate variables.

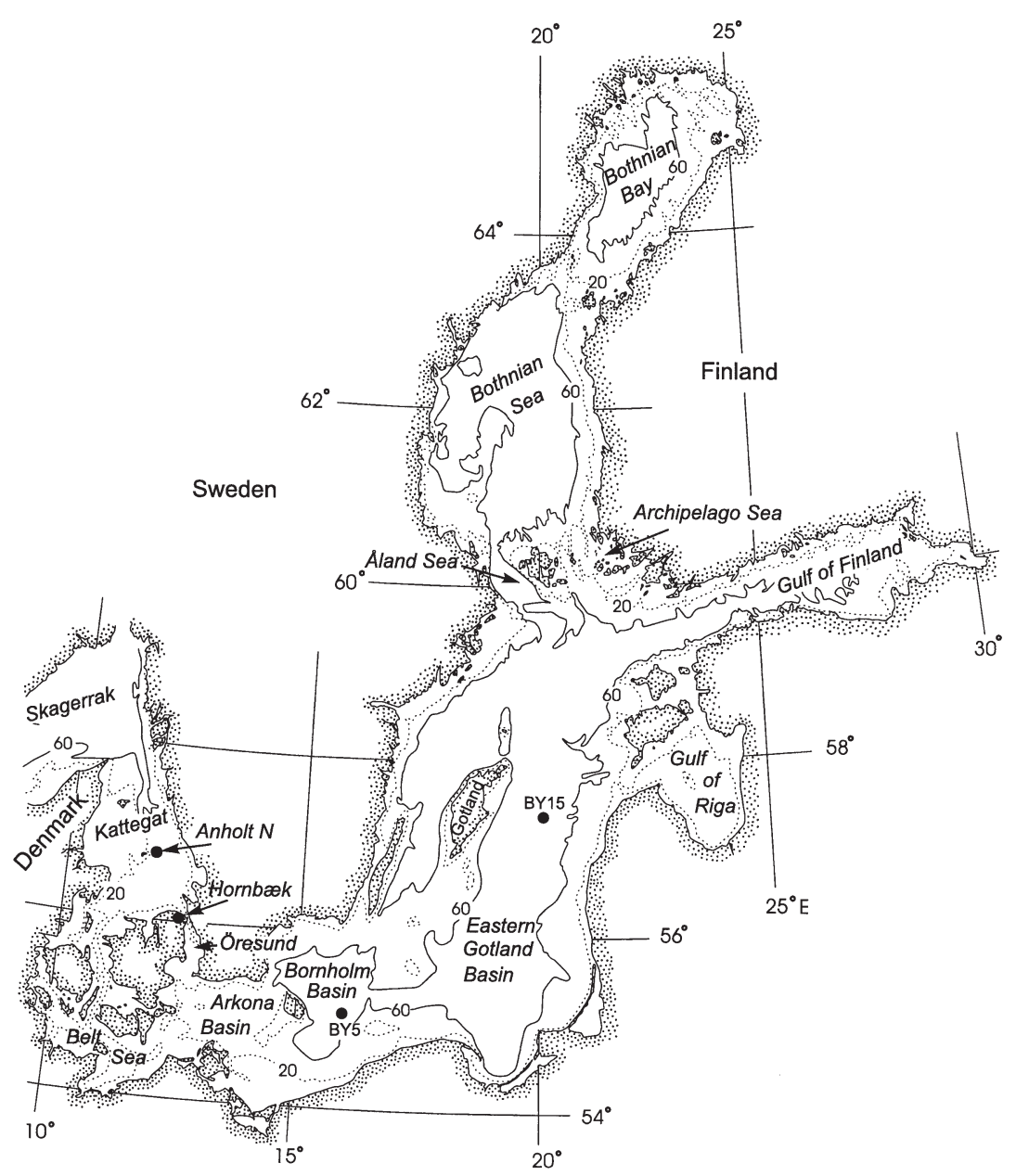

Fig. 1. Map of the Baltic Sea showing the location of hydrographical stations and areas used in analysis
Force-response relations are discussed in Section 5. Concluding remarks related to Baltic Sea ocean climate modelling are made in Section 6.

\section{DESCRIPTION OF THE BALTIC SEA}

The hydrographic state of the Baltic Sea is to a large extent determined by the net freshwater input in combination with the narrow connection to the open ocean. This results in a brackish water type with a salinity much lower than ocean salinity. A description of the physical oceanography of the Baltic Sea can be found in e.g. Kullenberg (1981), Stigebrandt (1995) and Rodhe (1998). Only a short description is given here.

Fig. 1 shows the bathymetry of the Baltic Sea. Hydrographic observation sites, from which historical data are taken for this study, are indicated. The connection between the North Sea and Baltic Sea is through the shallow Kattegat, with an average depth of $\sim 20 \mathrm{~m}$, and through the narrow and shallow Danish Straits. The deepest connection is through the Belt Sea, with a sill depth of $18 \mathrm{~m}$. In addition there is a connection through Öresund, with a sill depth of $8 \mathrm{~m}$. The Baltic Sea itself can be divided into the Baltic proper, consisting of the Arkona, Bornholm and Gotland Basins, freely connected to the Gulf of Finland, and the Gulf of Bothnia. The latter consists of the Alland Sea, the Archipelago Sea, the Bothnian Sea and Bothnian Bay. The Gulf of Riga is a small basin connected to the Baltic proper. The volume of the Baltic proper is $\sim 70 \%$ of the total volume of the Baltic Sea if we include the Gulf of Finland and the Gulf of Riga.

The surface salinity of the Baltic Sea increases from $\sim 3 \%$ in the northernmost part of the Gulf of Bothnia to just below $10 \%$ inside the Danish Straits (Fig. 2). In these straits, and in the Kattegat, there is a strong gradient to the oceanic salinity found in the North Sea. The sills inside the Danish Straits prevent the high-saline water, found below the halocline in the Kattegat, from entering the Baltic Sea without considerable dilution by low-saline surface water (Fig. 3).

A conceptual model of the physical oceanography of the Baltic Sea is 


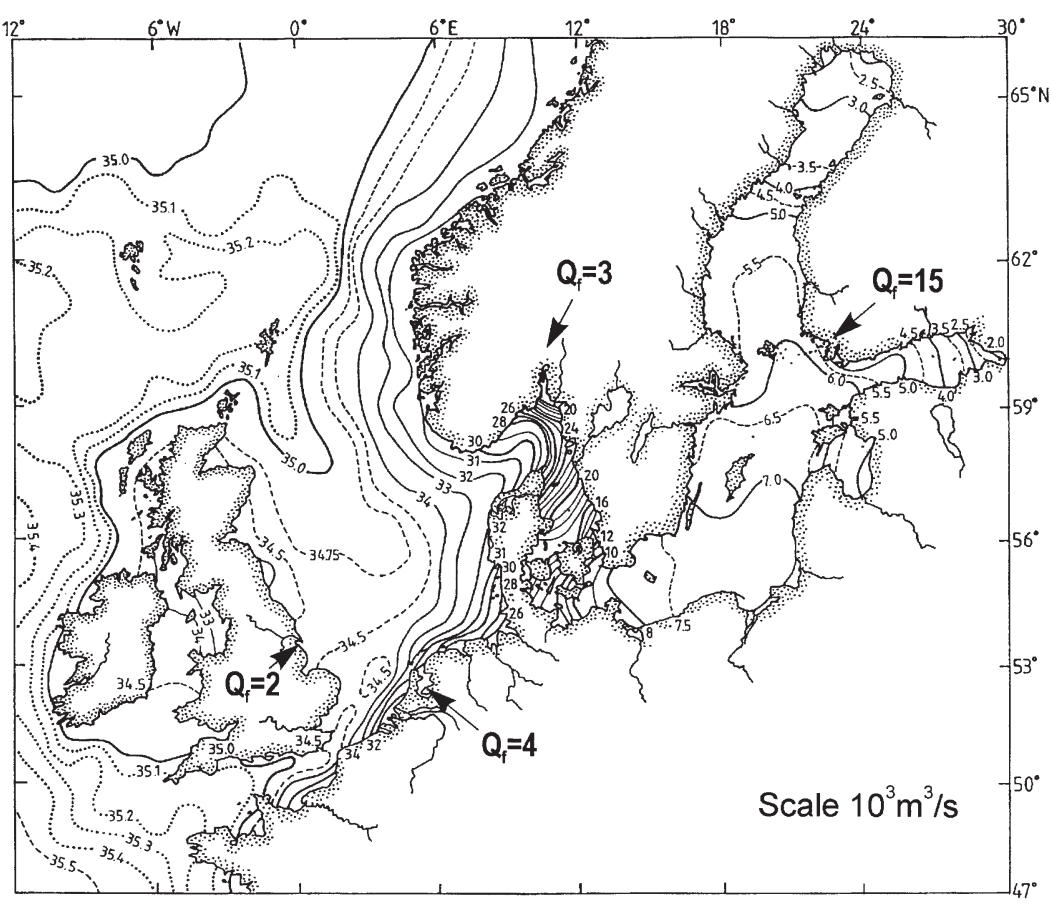

Fig. 2. Surface salinity distribution (\%). Also indicated is runoff $Q_{f}$ to the Baltic Sea $\left(15000 \mathrm{~m}^{3} \mathrm{~s}^{-1}\right)$, Kattegat and Skagerak $\left(3000 \mathrm{~m}^{3} \mathrm{~s}^{-1}\right)$, Danish, German, Dutch, and Belgian coasts $\left(4000 \mathrm{~m}^{3} \mathrm{~s}^{-1}\right)$, and east coast of England $\left(2000 \mathrm{~m}^{3} \mathrm{~s}^{-1}\right)$. Adapted from Rodhe (1998)

transport of salt from the Baltic Sea is proportional to the averaged outflow of water, whereas the amount of salt entering the Baltic also depends on the duration and strength of the inflows, i.e. the amount of water transported in each inflow event and the mixing in the inflow region.

After passing the sill the salty water descends into the basins of the Baltic proper through a number of contractions with different sill depths. At the same time the salinity decreases due to entrainment of ambient water. Only occasionally does the salinity of the inflowing water remain high enough to allow replacement of the deepest water (Wulff et al. 1990, Matthäus \& Franck 1992, Kõuts \& Omstedt 1993).

The connections between the different main basins of the Baltic Sea are wide and deep compared to the Danish Straits, and thus allow for much faster water exchange. This exchange is mainly forced by density differences. It is in this context important to note that a sill prevents the

shown in Fig. 4. The salinity stratification, the forcing of the system and the main processes involved are indicated. In the present study we will focus on large scale salinity features in relation to freshwater supply and the water exchange through the Danish Straits. This water exchange is dominated by alternating barotropic inflows and outflows. It is externally forced by sea level variations in the Kattegat and by the freshwater supply to the sea. The water exchange is modified by local tilting of the Baltic Sea surface and also to some extent by baroclinic effects related to the density difference between the Baltic Sea and the Kattegat. The instantaneous flow is typically of the order 10 times the net outflow, which, on average, equals the freshwater supply to the Baltic Sea. For a detailed analysis of the dynamics of Kattegat, see e.g. Gustafsson (2000a,b).

The halocline inside the Danish Straits is situated far below sill depth. This implies that outflowing water consists of low-saline Baltic Sea surface water, which shows small salinity variations with time. The salinity of the water passing the sill towards the Baltic Sea, on the other hand, increases with time during inflows. This asymmetry between in- and outflow events has an important consequence on the salt budget. The high-saline deep water in the Baltic proper from reaching the depths of the Gulf of Bothnia.

\section{DATA AND METHODS}

The data used for this statistical analysis are summarized in Table 1. Daily salinity measurements from the Danish lightship 'Anholt N', located in the middle of Kattegat, and cruise data for salinity and oxygen from
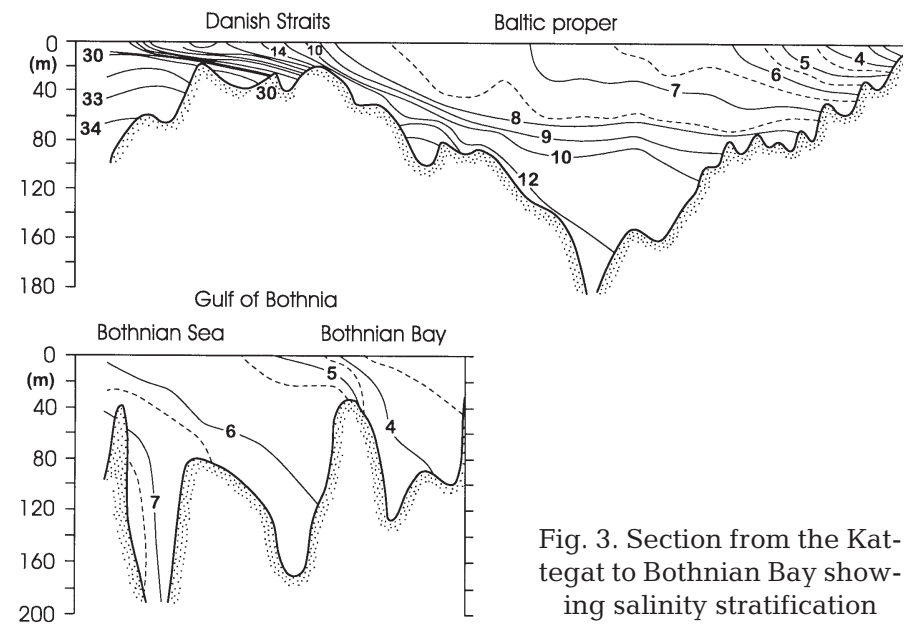

Fig. 3. Section from the Kattegat to Bothnian Bay showing salinity stratification 


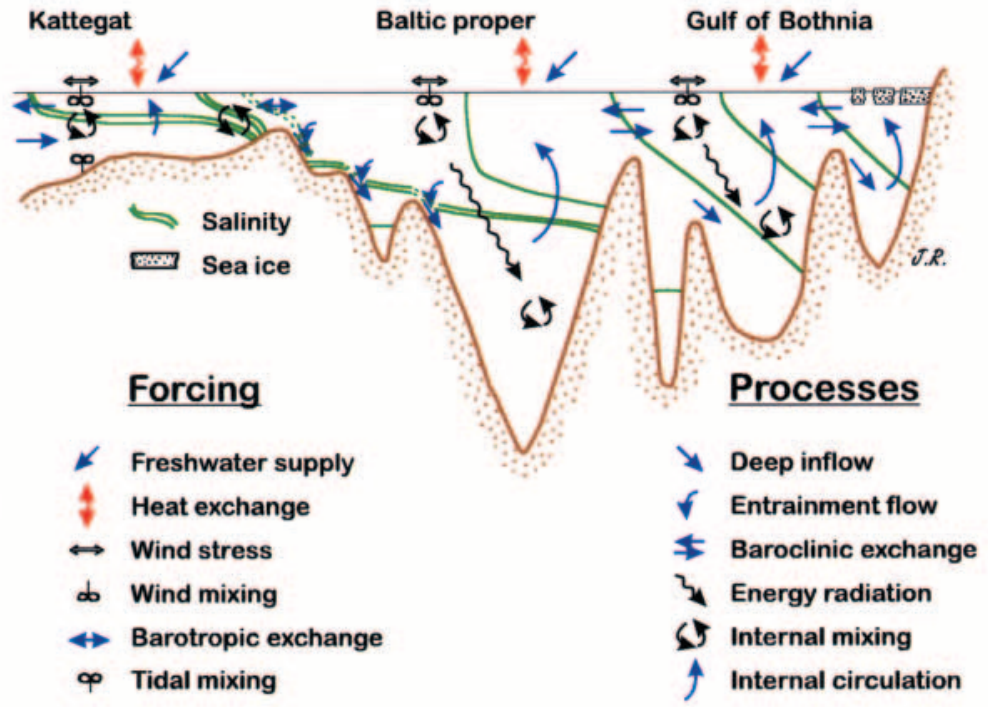

Fig. 4. Conceptual model of the Baltic Sea. Green lines show salinity stratification; presence of sea ice indicated in Bothnian Bay

a $1^{\circ}$ square around the regularly visited station BY15, located east of Gotland, are used in the analysis (see Fig. 1). The data from BY15 have been extracted from the Baltic Environmental Database (BED). The observations from these 2 areas are assumed to represent conditions in the Kattegat and Baltic Sea respectively. In addition to the data in Table 1, a shorter time series covering 10 yr with salinity profiles from all major subbasins in the Baltic Sea is used to verify how well BY15 represents the Baltic Sea as a whole. These are also taken from BED in $1^{\circ}$ squares in the centre of each basin. There is a slight under-representation of available profiles for some of the winter months (December and January), and there are no data during parts of the first and second world wars. Furthermore, there are much more data during the 1970s than during any other period. Generally, data coverage is denser from the 1950s onwards.

The sea level data from Hornbaek, located in the Kattegat (see Fig. 1), are daily-observed sea levels, and these are used to calculate the barotropic water exchange between the Kattegat and the Baltic Sea. This series covers the 1891 to 1998 period. The original time series was converted into the NH60 height system (Ekman 1994).

Apart from using the salinity as such, we also calculate the freshwater storage of the Baltic Sea and the Kattegat. This is defined as the amount of freshwater needed to dilute water with a specified background salinity in order to achieve the observed salinity. The reason why we use the freshwater storage is that it is an integrated quantity well suited for discussions of the Baltic Sea climate. When calculating the total freshwater volume the freshwater height in each profile is weighted by means of a mean hypsographic curve for the Baltic Sea. The freshwater height $F$ is calculated as:

$$
F=\frac{1}{S_{\text {ref }}} \int_{0}^{D} \max \left(\left[S_{\text {ref }}-S(z)\right], 0\right) \mathrm{d} z
$$

where $S_{\text {ref }}$ is a reference salinity, $D$ is the water depth, and $S(z)$ is the salinity of the current profile at depth $z$. The freshwater storage is calculated for the Baltic Sea and the Kattegat using BY15 and Anholt N respectively. To elucidate the representativeness of BY15 for the whole Baltic Sea we also compute the freshwater volume in all major sub-basins separately, with their own hypsographic curves, to compare these with the total volume obtained by using BY15 only. The comparison was done for the 1977 to 1987 period, with good data coverage in all sub-basins. The result of this can be seen in Fig. 5. The 2 curves follow each other well and the average difference is very small between the 2 curves, i.e. $\sim 219 \mathrm{~km}^{3}$ or some $2 \%$ of the total freshwater content. We therefore feel confident in using BY15 to represent the Baltic Sea as a whole, and we simply add a constant factor of $219 \mathrm{~km}^{3}$ to the calculated volumes (dotted line in Fig. 5). The same comparison is not done for the Kattegat due to lack of salinity data.

The sea level and runoff data are used to calculate the instantaneous barotropic transports through the Danish Straits (see Stigebrandt 1992). The sea level in the Baltic Sea $h_{\mathrm{b}}$ is calculated from

$$
\frac{\mathrm{d} h_{\mathrm{b}}}{\mathrm{d} t}=\frac{h_{\mathrm{k}}-h_{\mathrm{b}}}{\sqrt{\left|h_{\mathrm{k}}-h_{\mathrm{b}}\right|}} \frac{A}{Y} \sqrt{\frac{2 g}{(1+\kappa)}}+\frac{Q_{f}}{Y}
$$

where $h_{\mathrm{b}}$ and $h_{\mathrm{k}}$ are the sea levels in the Baltic Sea and the Kattegat respectively, $A$ is the cross sectional area of the channel, and $\kappa$ is a friction coefficient. The area of the Baltic Sea is $Y, g$ is the acceleration due to grav-

Table 1. Time series used in the analysis. DMI: Danish Meteorological Institute, SMHI: Swedish Meteorological and Hydrological Institute, BED: Baltic Environmental Database

\begin{tabular}{|lccc|}
\hline Variable, Area & Period & Resolution & Source \\
\hline Salinity, Anholt N & $1886-1985$ & Daily/monthly & DMI \\
Salinity and oxygen, BY15 & $1902-1996$ & Daily/monthly & BED \\
Sea level, Hornbaek & $1891-1993$ & Daily & SMHI \\
River runoff, Baltic & $1920-1990$ & Monthly & SMHI \\
\hline
\end{tabular}




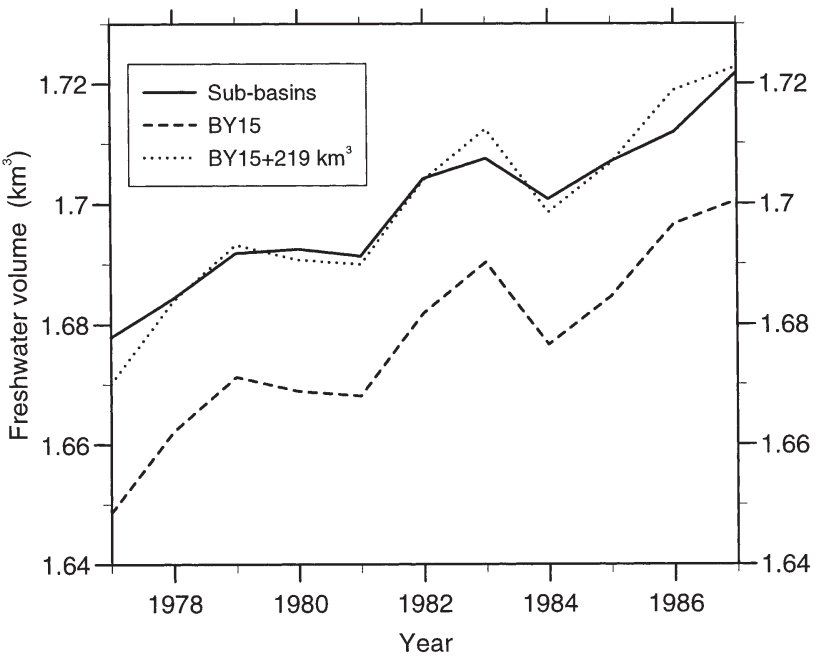

Fig. 5. Annual mean freshwater storage in the Baltic Sea for 1977 to 1987 calculated in 2 ways; firstly by using separate basins (Arkona and Bornholm basins, Baltic Proper, Bothnian Sea, and Bothnian Bay) with their own hydrographic measurements and hypsographic curves (solid line), and secondly by using BY15 only, together with a mean hypsographic curve for the whole Baltic Sea (dashed line). The difference is $\sim 2 \%$ of total freshwater content. Dotted line shows BY15 calculation plus the mean difference of $219 \mathrm{~km}^{3}$

ity, and $Q_{f}$ is the runoff to the Baltic. The sea level difference between the Baltic Sea and Kattegat is used to estimate the barotropic flow $Q$ as

$$
Q=K_{q} \frac{h_{\mathrm{k}}-h_{\mathrm{b}}}{\sqrt{\left|h_{\mathrm{k}}-h_{\mathrm{b}}\right|}}+Q_{f}
$$

where $K_{q}$ is a constant obtained by matching the calculated sea level in the Baltic Sea with observations (for details see Stigebrandt 1992). The barotropic water exchange is only calculated for 1921 to 1990 as the runoff data only cover this period. Neglecting the net precipitation in $Q_{f}$ gives a small error in the mean of $Q$ but does not affect the varying barotropic inflows and outflows.

\section{PRESENTATION OF THE TIME SERIES}

\subsection{River runoff}

Bergström \& Carlsson (1994) give a comprehensive discussion of the river runoff to the Baltic Sea and its different sub basins making use of historical data. The present analysis is based on a time series of the total runoff to the Baltic Sea covering the years 1921 to 1990, which is a composite of the data presented in Bergström \& Carlsson (1994) and Mikulsky (1982).

Fig. 6 shows the annual mean river runoff to the Baltic Sea, together with a 5 yr running mean. The

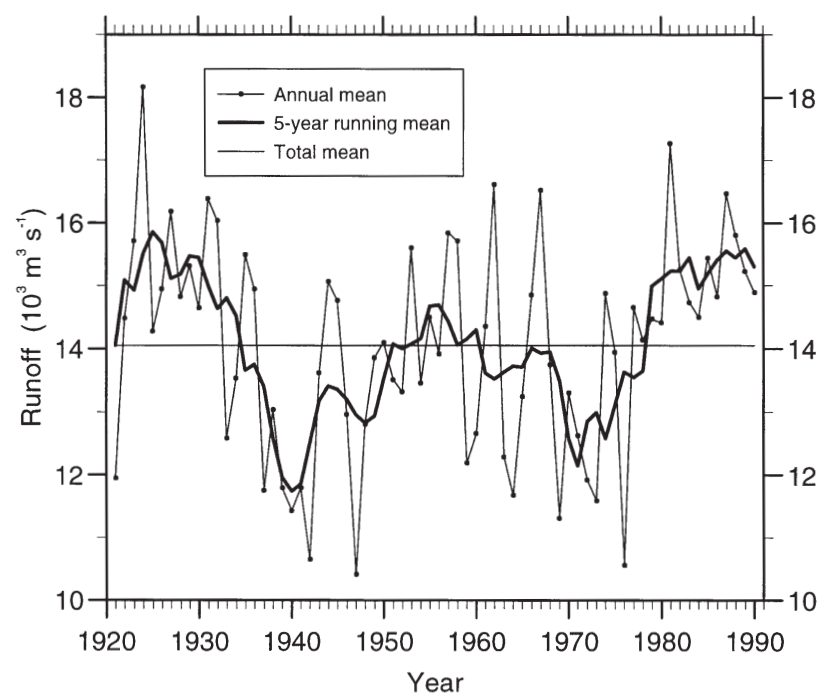

Fig. 6. Annual mean river runoff to the Baltic Sea (line with dots). 5 yr running mean (thick line) and total mean over whole period (thin line) also shown

overall mean is about $14000 \mathrm{~m}^{3} \mathrm{~s}^{-1}$ (or $15200 \mathrm{~m}^{3} \mathrm{~s}^{-1}$ including the Kattegat and the Danish Straits, not shown here). Fig. 7 shows the frequency of yearly means in intervals of $500 \mathrm{~m}^{3} \mathrm{~s}^{-1}$. The standard deviation, calculated from the yearly means, is $\sim 1680 \mathrm{~m}^{3} \mathrm{~s}^{-1}$. Looking at Fig. 6 we see variability of $\sim 30 \%$ on a time scale of a few years and almost the same variability on a time scale of a few decades. There is certainly no significant long-term trend during this period. Maximum and minimum annual runoff for the whole period is 18200 and $10400 \mathrm{~m}^{3} \mathrm{~s}^{-1}$ respectively.

We have to add the net precipitation to the river runoff in order to get the total freshwater supply to the Baltic Sea. The interannual variation of the net precipitation is now under study within BALTEX (Anon.

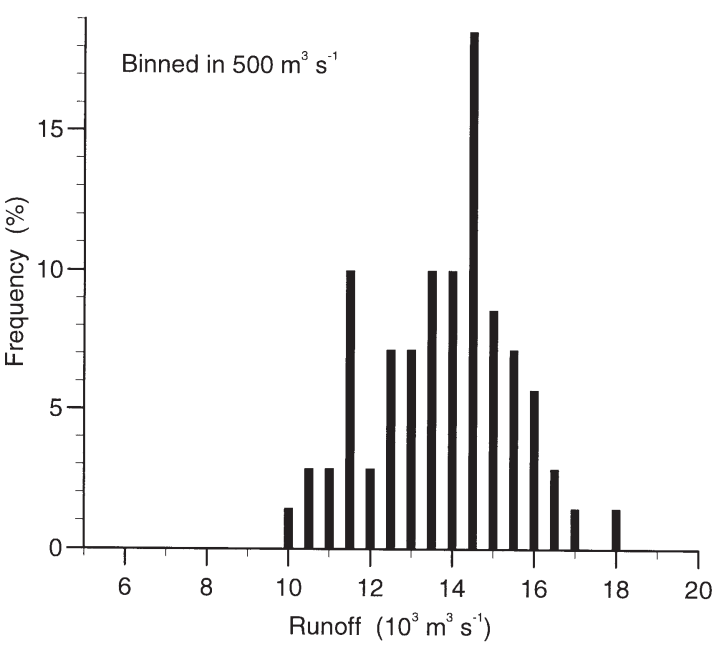

Fig. 7. Distribution of annual mean runoff for 1920 to 1990 
1995). A recent investigation by Omstedt et al. (1997) points to a long-term average net precipitation (precipitation minus evaporation) of $\sim 2000 \mathrm{~m}^{3} \mathrm{~s}^{-1}$. Interannual variability is large, with values ranging from $\sim 500$ to $4000 \mathrm{~m}^{3} \mathrm{~s}^{-1}$. Taking into account river runoff and net precipitation it is thus evident that it is within the natural variability of the system to have annual freshwater supplies ranging from $10000 \mathrm{~m}^{3} \mathrm{~s}^{-1}$ up to about $20000 \mathrm{~m}^{3} \mathrm{~s}^{-1}$ and to have periods with large positive and negative trends on decadal time scales. In the statistical analyses below we only use river runoff. The reason for this is that there is no reliable long-term time series of net precipitation available.

\subsection{Water exchange through the Danish Straits}

There are no direct observations of the flow through the Danish Straits suitable for use in the present analyses. We have therefore used observed sea level at Hornbaek in the southern Kattegat in a simple model to construct a time series of the barotropic flow. The method is described in Section 3. We know from observations that the barotropic component of the flow dominates in the shallow parts of the straits, where most of the fall in sea level occurs. Thus, the barotropic flow should, on average, give a net outflow of roughly the same magnitude as the net freshwater supply to the Baltic Sea. However, this net flow is the difference between a large intermittent outflow and an intermittent inflow that is nearly as large. Fig. 8 shows estimated yearly means of barotropic outflow from the Baltic Sea together with a 5 yr running mean. The mean value of this flow, $80 \times 10^{3} \mathrm{~m}^{3} \mathrm{~s}^{-1}$, is $\sim 5$ times

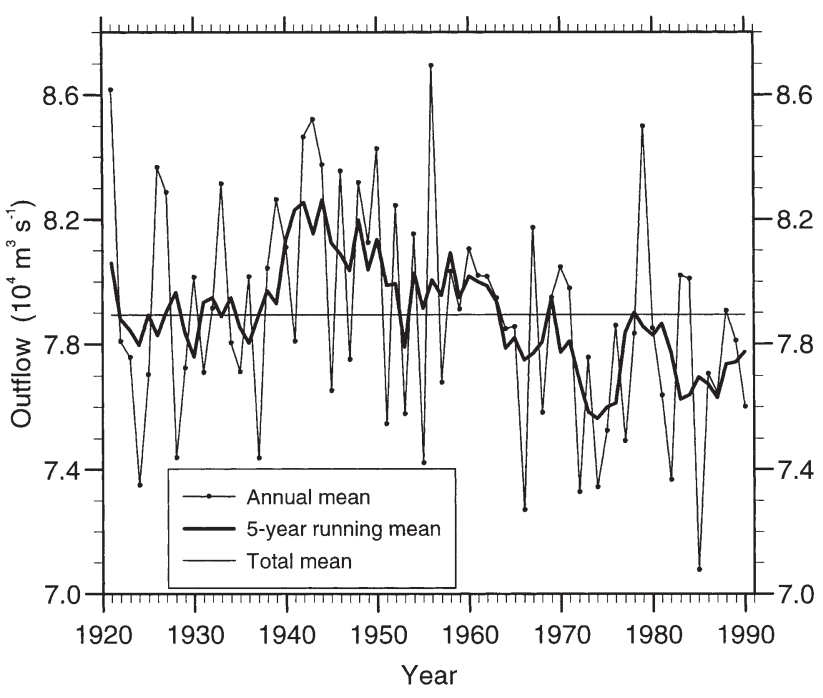

Fig. 8. Calculated annual mean gross outflow from the Baltic Sea

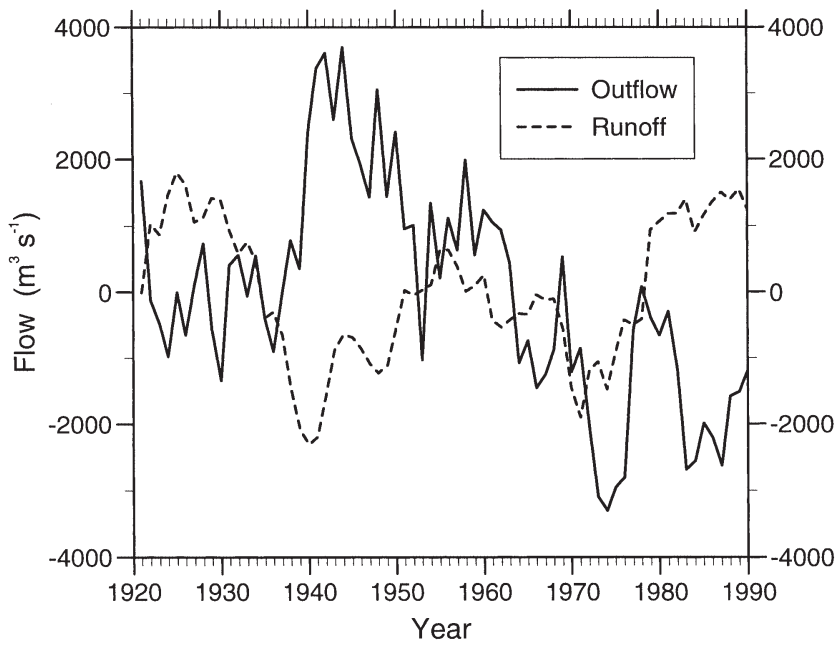

Fig. 9. Perturbations of runoff to and gross outflow from the Baltic Sea (5 yr running means)

larger than the freshwater supply, which is $14 \times 10^{3} \mathrm{~m}^{3}$ $\mathrm{s}^{-1}$. The standard deviation is $3500 \mathrm{~m}^{3} \mathrm{~s}^{-1}$, which is about twice that for the river runoff. Variations over a few years dominate but there are also variations over several decades. There is no significant trend when looking at the whole period, though there is a general decrease from the mid-1940s to the mid-1970s.

In Fig. 9 we compare the 5 yr running mean perturbations of river runoff and the barotropic outflow through the Danish Straits. From this presentation it is clear that the variations of these 2 flows are of the same magnitude, though the mean values differ considerably in magnitude. Turning to the time development of these flows, one might have expected that the variations of the outflow were to some extent forced by variations in river runoff, i.e. high river runoff would imply high outflow through the Danish Straits. This is obviously not the case. Looking at Fig. 9 the opposite correlation is apparent for the low-frequency part of the variations, though the correlation is weak $(-0.4)$. The explanation for this is that the barotropic flow through the Danish Straits is to a large extent externally driven by the comparatively high frequency sea level variations in the Kattegat and not influenced much by the low-frequency variations of the freshwater input to the Baltic Sea. We therefore conclude that interannual variations in forcing related to sea level fluctuations in the Kattegat, which in turn reflect the alternating wind-forced sea level set-up in the North Sea, are weakly negatively correlated with river runoff and possibly to net precipitation over the Baltic Sea drainage area. This, however, is a subject for future investigations.

We do not show information about the inflow through the Danish Straits corresponding to what is 


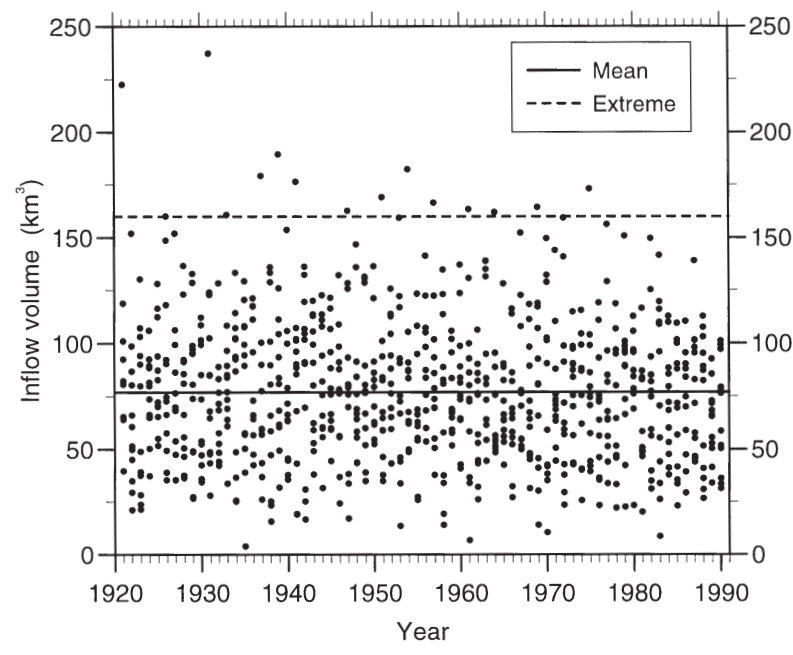

Fig. 10. Scatter plot of all modelled consecutive inflow events

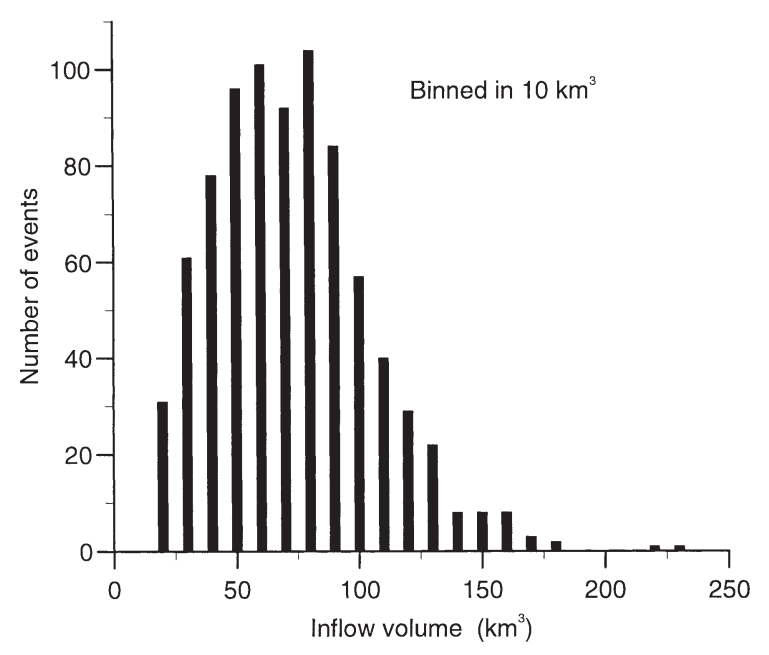

Fig. 11. Distribution of inflow events

shown in Fig. 9 for the outflow. It suffices to note that the annual averaged barotropic outflow must equal the sum of net freshwater supply and the inflow. Instead we focus on the strength of the different inflows. During the first part of an inflow, the flow consists of lowsaline Baltic Sea surface water that just passed the sill in the other direction. After that the salinity increases during the time of the inflow. The length of the inflow event is therefore of interest when discussing the inflow of salt, or specifically the amount of water passing the Danish Straits during each inflow event. Fig. 10 shows the estimated volume transport during all inflow events. The average inflow-event transport is indicated. We see a rather even distribution with time. The frequency distribution related to this is shown in Fig. 11. The events with the largest inflow volumes can be expected to have carried exceptionally high salinity and thus have been responsible for renewal of the deepest basin water. An arbitrary limit of $160 \mathrm{~km}^{3}$, defining extreme inflows, is inserted in Fig. 10 (dashed line). Extreme inflows are discussed in relation to the time development of salinity and oxygen concentration at $200 \mathrm{~m}$ in the Eastern Gotland Basin (see Section 4.4, Fig. 13).

\subsection{Salinity}

Fig. 12 shows the yearly mean salinity at specific depths in the Kattegat and in the Baltic proper. In the Kattegat we have chosen to show the surface salinity and the salinity at $20 \mathrm{~m}$. The latter is as close to the sill depth of the Baltic Sea $(18 \mathrm{~m})$ as is possible using the lightship observations with $5 \mathrm{~m}$ depth intervals. We have chosen 0 and $50 \mathrm{~m}$ to represent the almost vertically homogeneous surface layer of the Baltic proper. The observations at $100 \mathrm{~m}$ represent the more or less continuously renewed upper part of the Baltic Sea deep water and those at $200 \mathrm{~m}$ represent the basin water with only intermittent water renewal. We note first the large difference in salinity between the Baltic Sea and the Kattegat. The average salinity at this position in Kattegat is $21.0 \%$ in the surface layer and $31.6 \%$ in the deep layer. At the hydrographic station representing the Baltic proper the average salinity is $7.2 \%$ in the surface layer and $12.3 \%$ at a depth of $200 \mathrm{~m}$. It is evident that there is considerable entrainment of outflowing Baltic Sea surface water into the inflowing water from the Kattegat before the latter penetrates into the deep basins of the Baltic Sea. From

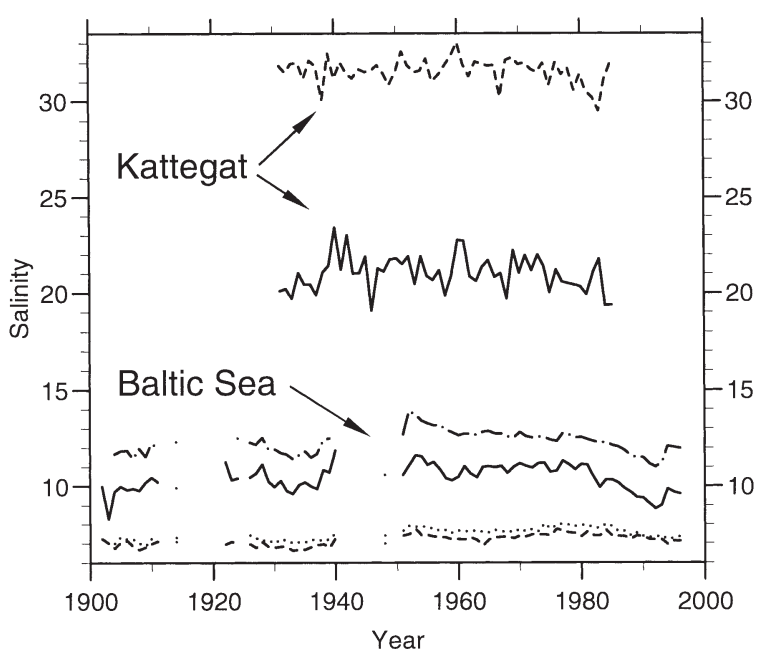

Fig. 12. Annual mean salinities (\%) from the Eastern Gotland Basin (BY15) (from bottom and up) at 0, 50, 100, and $200 \mathrm{~m}$ depth, and from Kattegat at 0 and $20 \mathrm{~m}$ depth 


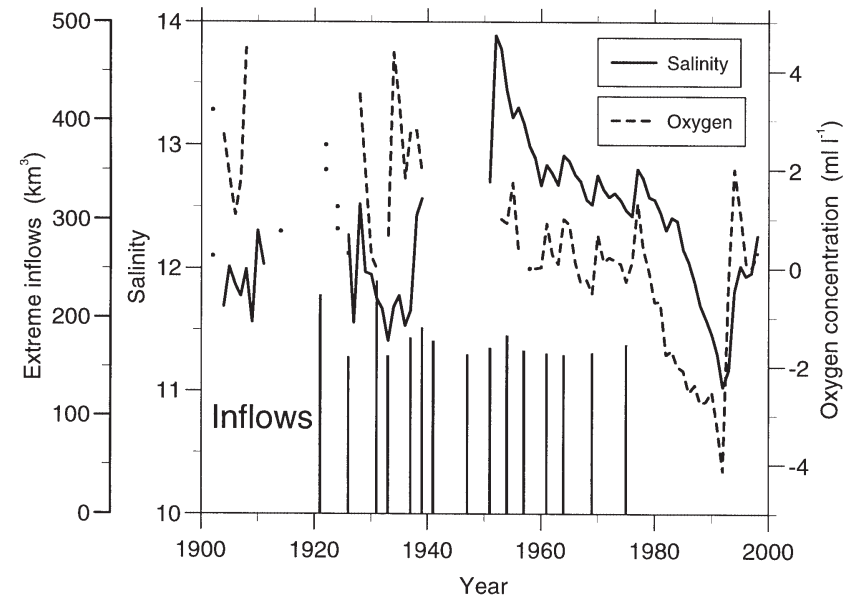

Fig. 13. Extreme inflows (bars) and annual-mean deep-water oxygen concentration ( $\mathrm{ml} \mathrm{l}^{-1}$, dashed line) and salinity (\%, solid line). Inflow calculations only for 1920 to 1990

Fig. 12 we also see that the variations of salinity on a time scale of a few years dominate over long-term variations and trends in the Kattegat. In the Baltic Sea, on the other hand, trends over decades are clearly visible especially in the deep water (cf. discussion in Section 4.4). Interannual salinity variations in the Baltic Sea during the 1954 to 1990 period have been discussed in more detail by Samuelsson (1996).

\subsection{Oxygen concentration and deep water inflows}

The deep-water oxygen content is a good indicator of periods of deep-water stagnation in relation to periods with deep-water renewal. For this reason, time series of oxygen and salinity at $200 \mathrm{~m}$ at the hydrographic station BY 15 are shown in Fig. 13. Inflow events with estimated transport exceeding $160 \mathrm{~km}^{3}$ (i.e. 'extreme' inflows, see Fig. 11) are indicated. Most of these are followed by increasing oxygen content and salinity. Also, most of the events with a clear increase in these 2 variables are found after large inflows. The calculations of inflows stopped at 1990, implying that the inflow 1993 is not captured. When analysing Fig. 13 we must bear in mind that the time resolution is $1 \mathrm{yr}$ and that inflow events could have started in the beginning or at the end of the specific year. However, our conclusion is that we have chosen the right level for the discrimination of large inflows.

Matthäus \& Franck (1992) present a statistical analysis of what they call 'major' Baltic inflows. These were defined as those that represent definite conditions at the Darss sill, with respect to salinity and duration. They defined an inflow index, using the salinity stratification at the sill and the length of the inflow, and found quite a good correlation between the index and the renewal of the deep-basin water. They also estimated the amount of water transported into the Baltic Sea during each of 90 major Baltic inflow periods from 1897 to 1976 . The transport in these inflows ranges from 80 to $360 \mathrm{~km}^{3}$ with an average of $\sim 200 \mathrm{~km}^{3}$. However, their figures are not exactly comparable to what is calculated in the present study. They calculated the transported volume of water during what they defined as an inflow period, which could be interrupted by short-term reversals of the current, whereas the calculations in the present study stop when the flow reverses. Also, the volume transports are calculated in different ways; they estimate the flow by combining the changes in sea level at Landsort, assumed to represent the Baltic Sea, with the monthly mean river runoff for the period 1921 to 1975 . The present study, on the other hand, uses a dynamical model including true river runoff to calculate the flow.

The classification used in the present study might be better suited for climate change scenarios than the index defined by Matthäus \& Franck (1992); the inflow index in the present study can be derived from external forcing, whereas the latter relies on observed salinity inside the Danish Straits. In the future it should be possible to relate the present index to the large-scale atmospheric circulation pattern together with the net precipitation over the Baltic Sea drainage area.

\subsection{Freshwater storage}

The total freshwater volume stored in the Baltic Sea is shown in Fig. 14 as annual mean volume and as a 5 yr running mean. The average freshwater volume is $1.7 \times 10^{4} \mathrm{~km}^{3}$ which corresponds to about $80 \%$ of the

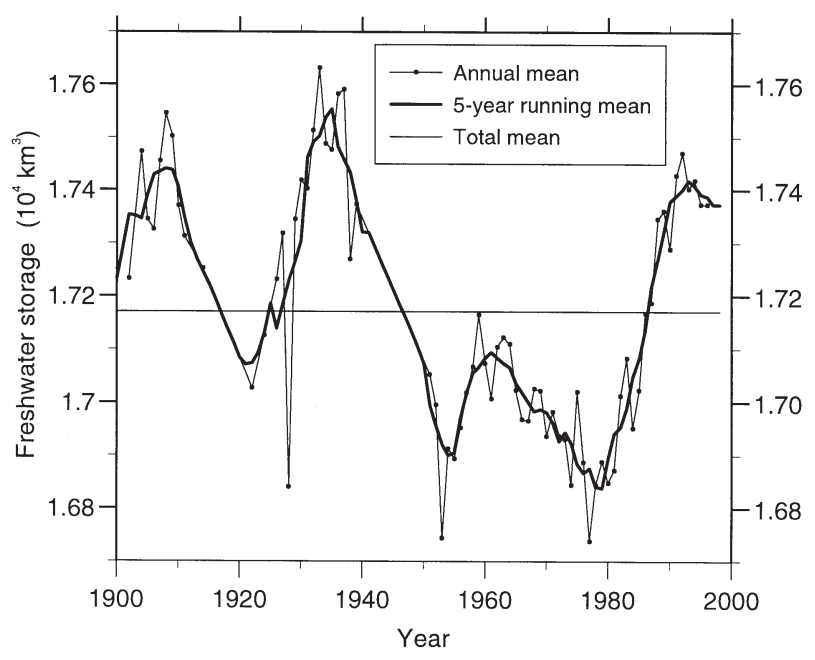

Fig. 14. Annual mean freshwater storage in the Baltic Sea 


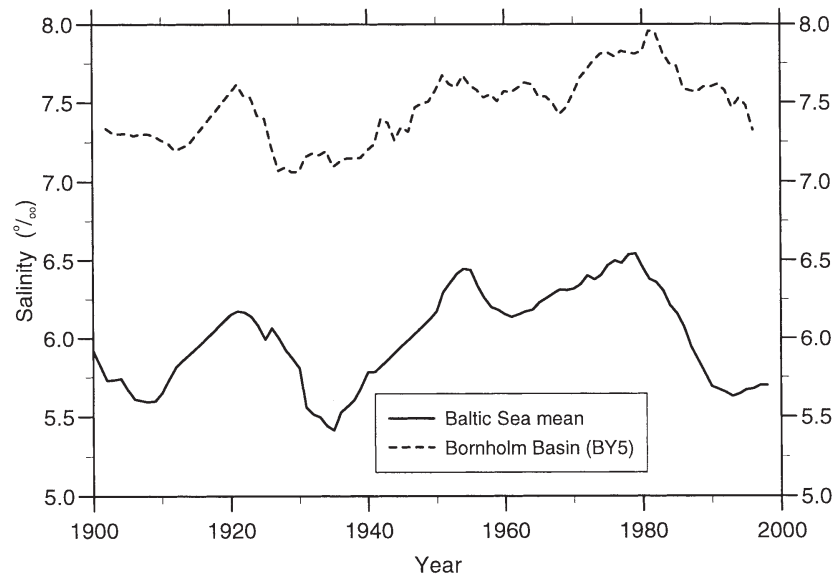

Fig. 15. Surface salinity in the Bornholm Basin (BY5) and mean salinity of the Baltic Sea, calculated from freshwater content. Both series 5 yr running means

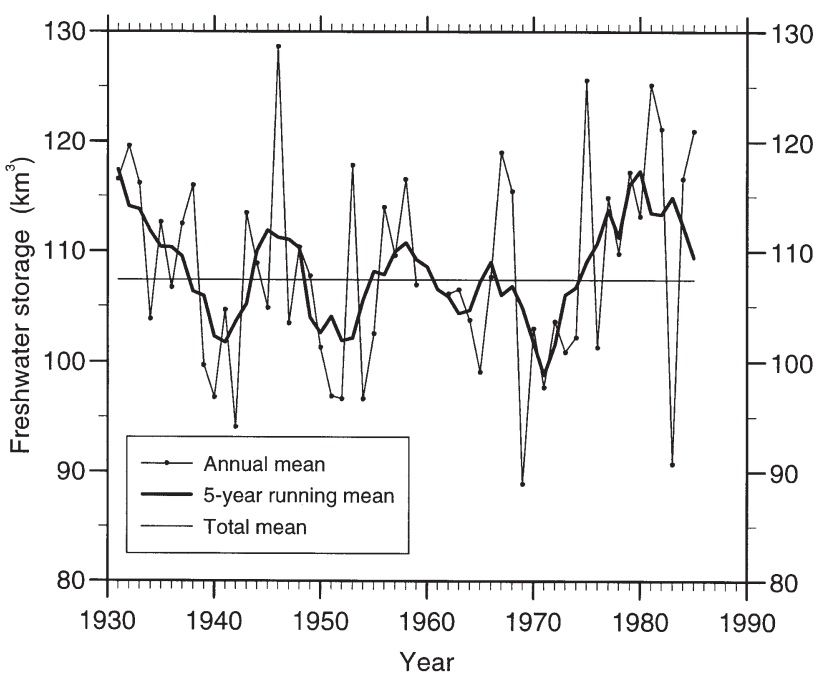

Fig. 16. Annual mean freshwater storage in the Kattegat calculated from salinity observations at Anholt N

total volume of the Baltic Sea. A freshwater residence time can be calculated by relating the average freshwater storage to the yearly averaged freshwater supply, which is about $16000 \mathrm{~m}^{3} \mathrm{~s}^{-1}$. The residence time then becomes about $34 \mathrm{yr}$.

The freshwater storage can be used to calculate the mean salinity of the Baltic Sea. This is shown as $5 \mathrm{yr}$ running mean in Fig. 15 together with the surface salinity in the Bornholm Basin, situated close to the connection to the Kattegat. We note that the mean salinity of the Baltic Sea has varied between $\sim 5.5$ and $6.5 \%$ during the 20th century. We also see that the surface salinity in the southern part of the Baltic Sea (BY5 in the Bornholm Basin, see Fig. 1) is well correlated with the average salinity, which was calculated using vertical salinity profiles east of Gotland. The best correlation is found for no time lag, and the coefficient is 0.75 . The similarity between average salinity and sea surface salinity in the Bornholm Basin indicates that changes in freshwater storage primarily show up as changes in salinity, not as changes in stratification e.g. halocline depth.

Fig. 16 shows the time series of freshwater storage in the Kattegat. Note here that the magnitude is estimated from 1 hydrographic station and not corrected for horizontal gradients, as was the case for the Baltic Sea calculation. However, the variability is probably captured correctly, and is $\sim 20 \%$ for variations over a few years as well as over decades. The magnitude of the freshwater storage indicates a residence time of 2 mo if related to the freshwater supply to the Baltic Sea, whose freshwater must pass through the Kattegat.

\section{DISCUSSION OF FORCE-RESPONSE RELATIONS}

We now discuss the freshwater budget of the Baltic Sea. The source of freshwater is river runoff, net precipitation, and the inflow of freshwater equivalents through the Danish Straits. The sink is the outflow of freshwater equivalents. Mixing in the Baltic Sea determines the freshwater content of the outflowing water and the mixing between the outflowing water and the high saline water entering the Kattegat determines the amount of freshwater returning to the Baltic Sea with the inflows.

The freshwater flows, as well as the water flows as such, should match in a steady state. This was somewhat differently formulated in the relations given by Knudsen (1900). He used observed average salinity of 8.7 and $17.4 \%$ in the out- and inflowing water respectively in his classical calculation. In a more recent calculation, Kõuts \& Omstedt (1993) use 8.5 and 16.9\%o as salinities representative for the period 1970 to 1990 . The magnitude of the inflow is the same as the freshwater supply and the outflow is consequently 2 times that with this relation between the salinities. This solution is still accepted as giving a fairly good diagnosis of salt and water budgets of the Baltic Sea. We note here that the average gross in- and outflows, as reported in Section 4.2, are 2 to 3 times greater than what is predicted by the Knudsen relations. This indicates that most of the transport during each of the to and fro movements through the Danish Straits contains water having nearly the same salinity as the previous flow in the opposite direction, and thus does not contribute to the exchange of freshwater.

The Knudsen solution does not contain any information about freshwater storage and its changes as a response to changes in forcing, which in the case study 
are the freshwater supply and the barotropic flow through the Danish Straits. The changes with time are now discussed using the 5 yr running mean time series. We use the river runoff to represent the freshwater supply (note that this implies an underestimate of $\leq 10 \%$ ). First we recall that the variations of river runoff and outflow through the Danish Straits are of the same magnitude (see Fig. 9, Section 4.2.) We also recall that the net outflow is much smaller than the gross outflow (i.e. much of the water is transported in and out with nearly the same salinity) and that the outflowing water is not pure freshwater. Doing so, we immediately conclude that changes of the river runoff must have dominated over changes of the gross in- and outflows in determining the changes of the freshwater storage. We consequently omit the inter-annual variations in water exchange through the Danish Straits in the following discussion.

The next question is whether the response is 'quasistationary' or 'truly time-dependent'. In the quasi-stationary response the time dependence follows the time dependence of the forcing, which in our case is essentially the river runoff. This type of response should be expected for a system having much shorter residence time than the time scale of the variations in forcing. The Knudsen relations can be used for diagnoses of the variations in the quasi-stationary case. On the other hand, if the response time of the system is much larger, we should expect a truly time-dependent response and that the system absorbs the changing river runoff. The dominating time scale of the variations in freshwater supply (as shown in Fig. 6) is $\sim 30 \mathrm{yr}$, which is of the same magnitude as the residence time of the Baltic Sea. Thus, we would expect a response between the 2 extremes. To elucidate the nature of the response we have calculated the correlation between river runoff and freshwater content for different time lags. We have also made correlation calculations for the accumulated runoff perturbation, which has the same meaning as the correlation between runoff and the time derivative of freshwater content. The result is somewhat unexpected. We find that the runoff and the freshwater content are uncorrelated at zero time lag, whereas the accumulated runoff perturbation has a maximum correlation of 0.92 at zero time lag, i.e. the Baltic Sea seems to respond in a 'truly time-dependent' manner to variations in river runoff.

Fig. 17 shows the freshwater storage and accumulated river runoff perturbations. It is evident that they are not only well correlated but also that the magnitude of variations in freshwater content is largely determined by the accumulated runoff to the Baltic Sea. Looking at details we note that the dip in freshwater storage in comparison with accumulated river runoff during the 1950s coincides with a large inflow

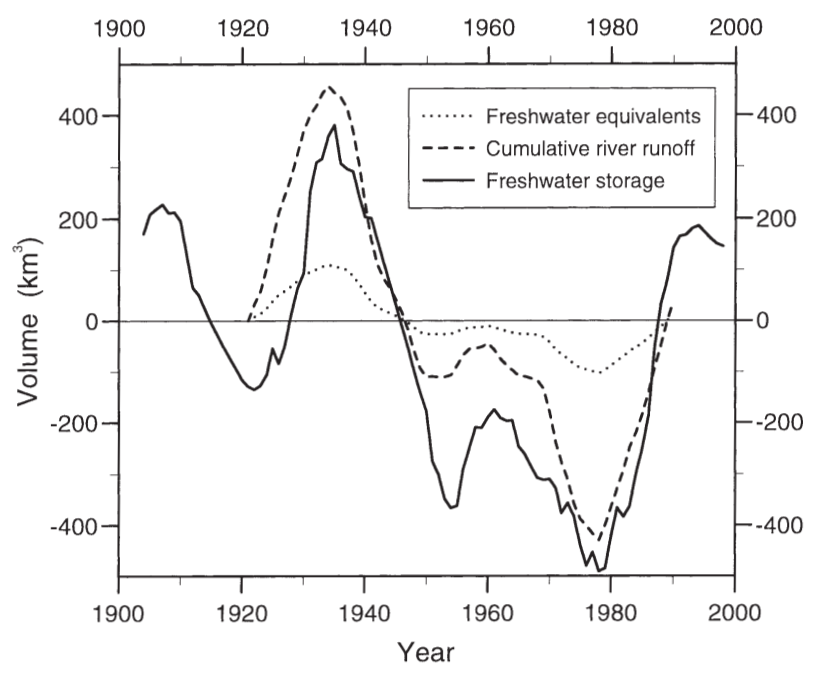

Fig. 17. Freshwater storage anomaly of the Baltic Sea, accumulated river runoff anomaly, and transport of freshwater equivalents out of the Baltic Sea calculated as $Q_{f}[1-$ $\left.\left(S_{\text {ref }}-S_{1}\right) / S_{\text {ref }}\right]$, where $S_{1}$ is the salinity of the outflowing surface water from the Baltic Sea to the Kattegat, set to a constant value of $8 \%$

of unusually salty water (cf. Section 4.3). The reduced dip at the end of the 1970s, on the other hand, coincides with the unusually long interval between large inflows.

The dotted line in Fig. 17 shows the expected variations in freshwater content if we also consider the variations of the net outflow of freshwater equivalents (i.e. water having a southern Baltic Sea surface salinity). This outflow is a necessary consequence of the varying freshwater supply to the Baltic Sea, for reasons of continuity. If there were no feedback from the outflowing water on the inflow of freshwater equivalents we would expect the freshwater content to follow the dotted line in Fig. 17. Instead we note that the freshwater content closely follows the accumulated perturbations of river runoff. Thus, there is a strong positive feedback from the freshwater content of the Baltic Sea on the return of freshwater equivalents with the inflows.

The freshwater residence time in the Kattegat is only a few months (see Section 4.5). Due to this short residence time, we expect the Kattegat to respond to changes in freshwater supply in a quasi-stationary way. This means that the freshwater storage varies in concert with the variations in supply. The function should be related to the dynamics of the outflow of surface water from the Kattegat. Discussion of this is outside the scope of the present study. The correlation between river runoff to the Baltic Sea, which must pass the Kattegat, is found to be 0.7 for the $5 \mathrm{yr}$ running mean. This result is an indication of the quasi-stationary response. 


\section{SUMMARY AND CONCLUSIONS}

Almost 100 yr of observational data for river runoff, water exchange through the Danish Straits (as calculated from sea level and river runoff data), salinity at different locations and oxygen content in the deep part of the Baltic proper have been analysed. Time series and some statistical properties have been calculated. These are intended to be used for validating control runs of climate models and to determine the significance of climate change scenarios.

The main conclusions from this analysis can be summarized as follows:

- Freshwater supply to the Baltic Sea shows large variations on time scales up to several decades. A consequence is that climate control scenarios must cover several decades, probably up to $100 \mathrm{yr}$, to capture the natural variability of present day climate.

- Water exchange through the Danish Straits, driven externally by sea level changes, shows relatively small variations and no trend during the century.

- Salinity of the Baltic Sea shows large-scale variations of $\sim 1 \%$ on a time scale of several decades. No long-term trend is found during the century.

- Variations in freshwater storage (i.e. mean salinity) in the Baltic Sea reflect the accumulated changes of the river runoff, seemingly without any damping, even on a time scale of several decades. This means that models of climate change must probably start integration from the present day state of the Baltic Sea in order to be realistic.

- The amount of water transported through the Danish Straits during inflow events can be used to discriminate those inflows that renew deep basin water in the Baltic proper. These flows can in turn be calculated from external forcing.

- Key processes determining the state of the Baltic Sea, in addition to the freshwater input, are barotropic water exchange through the Danish Straits and mixing between outflowing Baltic Sea surface water and inflowing Kattegat deep water.

Acknowledgements. SWECLIM Swedish Regional Climate Modelling Programme supported by MISTRA (Strategic Environmental Research Foundation) and SMHI (Swedish Meteo- rological and Hydrological Institute). Hydrographical data from Kattegat courtesy of DMI (Danish Meteorological Institute). Agneta Malm helped with the preparation of figures.

\section{LITERATURE CITED}

Anonymous (1995) Baltic Sea Experiment, BALTEX. Initial implementation plan. International Baltex Secretariat, Publ. No. 2, Geesthacht

Bergström S, Carlsson B (1993) Hydrology of the Baltic basin; inflow of freshwater from rivers and land for the period 1950-1990. Swedish Meteorological and Hydrological Institute, Rep Hydrol 7

Ekman M (1994) Deviation of mean sea level from the mean geoid in the transition area between the North Sea and the Baltic. Mar Geodesy 17:161-168

Gustafsson BG (2000a) Time-dependent modeling of the Baltic entrance area. 1. Quantification of circulation and residence times in the Kattegat and the straits of the Baltic Sea. Estuaries 23(2):231-252

Gustafsson BG (2000b) Time-dependent modeling of the Baltic entrance area. 2. Water and salt exchange of the Baltic Sea. Estuaries 23(2):254-267

Knudsen M (1900) Ein hydrographischer Lehrsatz. Ann Hydrogr Marit Meteor Bd:500-504

Kõuts T, Omstedt A (1993) Deep water exchange in the Baltic proper. Tellus 45A:311-324

Kullenberg G (1981) Physical oceanography. In: Voipio A (ed) The Baltic. Elsevier Oceanography Series 30, Elsevier, Amsterdam, p 135-181

Matthäus W, Franck H (1992) Characteristics of major Baltic inflows-a statistical analysis. Cont Shelf Res 12: $1375-1400$

Mikulsky Z (1982) River inflow to the Baltic Sea 1921-1975: summary list. Faculty of Geography and Regional Studies, University of Warsaw

Omstedt A, Meuller L, Nyberg L (1997) Interannual, seasonal, and regional variations of precipitation and evaporation over the Baltic Sea. Ambio 26:484-492

Rodhe J (1998) The Baltic and the North Seas: a process-oriented review of the physical oceanography. In: Robinson AR, Brink K (eds) The sea. John Wiley \& Sons, New York, p 699-732

Samuelsson M (1996) Interannual salinity variations in the Baltic Sea during the period 1954-1990. Cont Shelf Res 16:1463-1477

Stigebrandt A (1992) Bridge-induced flow reduction in sea straits with reference to effects of a planned bridge across Öresund. Ambio 21:130-134

Stigebrandt A (1995) The large-scale vertical motion of the Baltic Sea. In: Omstedt A (ed) First study conference on BALTEX. Conference proceedings. International Baltex Secretariat, Publ. No. 3, Geesthacht, p 28-47

Wulff F, Stigebrandt A, Rahm L (1990) Nutrient dynamics of the Baltic Sea. Ambio 19:126-133 